\title{
Gas phase UV absorption spectra for peracetic acid, and for acetic acid monomers and dimers
}

\author{
John J. Orlando*, Geoffrey S. Tyndall \\ Atmospheric Chemistry Division, National Center for Atmospheric Research, \\ P.O. Box 3000 Boulder, CO 80307, USA
}

Received 24 April 2002; received in revised form 14 September 2002; accepted 14 September 2002

\begin{abstract}
Absorption cross sections have been determined in the UV spectral region $(205-350 \mathrm{~nm})$ for gas phase acetic acid $\left(\mathrm{CH}{ }_{3} \mathrm{C}(\mathrm{O}) \mathrm{OH}\right)$ in its monomeric and dimeric forms $(270-345 \mathrm{~K})$, as well as for peracetic acid $\left(\mathrm{CH}_{3} \mathrm{C}(\mathrm{O}) \mathrm{OOH}, 248\right.$ and $\left.298 \mathrm{~K}\right)$. Analysis of acetic acid spectra recorded over a range of pressures (0.12-3.6 Torr), coupled with a prior knowledge of the dimerization equilibrium constant, allowed for the deconvolution of the monomer and dimer absorption spectra. The $298 \mathrm{~K}$ monomer spectrum consists of a maximum near $207 \mathrm{~nm}$ $\left(\sigma=1.4 \times 10^{-19} \mathrm{~cm}^{2}\right.$ per molecule), with monotonically decreasing cross sections at longer wavelengths. The dimer spectrum possesses a maximum located short of $205 \mathrm{~nm}$, with a peak intensity about double that of the monomer. The first gas phase spectrum of peracetic acid is also reported, which is similar to a previously published solution-phase spectrum. Measurable absorption extends to $340 \mathrm{~nm}$ at $298 \mathrm{~K}$, and it is determined that the tropospheric photolysis of this species will be a reasonably rapid process (lifetime $\approx$ weeks), which will play at least a minor role in its atmospheric destruction.
\end{abstract}

(C) 2003 Elsevier Science B.V. All rights reserved.

Keywords: Gas phase UV absorption; Peracetic acid; Acetic acid

\section{Introduction}

The oxidation of hydrocarbon species (both man-made and natural) in the earth's lower atmosphere leads to the generation of a number of secondary pollutants, including ozone and a multitude of partially oxidized oxygenand nitrogen-containing organic species [1-3]. Among this mix of organic species are the carboxylic and peroxycarboxylic acids, which are believed to be derived largely from the reactions of $\mathrm{HO}_{2}$ radicals with peroxyacyl species [4-7], e.g.:

$$
\begin{aligned}
& \mathrm{CH}_{3} \mathrm{C}(\mathrm{O}) \mathrm{O}_{2}+\mathrm{HO}_{2} \rightarrow \mathrm{CH}_{3} \mathrm{C}(\mathrm{O}) \mathrm{OOH}+\mathrm{O}_{2} \\
& \mathrm{CH}_{3} \mathrm{C}(\mathrm{O}) \mathrm{O}_{2}+\mathrm{HO}_{2} \rightarrow \mathrm{CH}_{3} \mathrm{C}(\mathrm{O}) \mathrm{OH}+\mathrm{O}_{3}
\end{aligned}
$$

The peroxyacyl radicals are generated either from the oxidation of aldehydes:

$$
\begin{aligned}
& \mathrm{OH}+\mathrm{CH}_{3} \mathrm{CHO} \rightarrow \mathrm{CH}_{3} \mathrm{C}(\mathrm{O})+\mathrm{H}_{2} \mathrm{O} \\
& \mathrm{CH}_{3} \mathrm{C}(\mathrm{O})+\mathrm{O}_{2}+\mathrm{M} \rightarrow \mathrm{CH}_{3} \mathrm{C}(\mathrm{O}) \mathrm{O}_{2}+\mathrm{M}
\end{aligned}
$$

\footnotetext{
* Corresponding author. Tel.: +1-303-497-1486; fax: +1-303-497-1411. E-mail address: orlando@ucar.edu (J.J. Orlando).
}

or from the decomposition of radicals generated in the oxidation of larger species, for example, acetone [8,9]:

$\mathrm{OH}+\mathrm{CH}_{3} \mathrm{C}(\mathrm{O}) \mathrm{CH}_{3}\left(+\mathrm{O}_{2}\right) \rightarrow \mathrm{CH}_{3} \mathrm{C}(\mathrm{O}) \mathrm{CH}_{2} \mathrm{O}_{2}+\mathrm{H}_{2} \mathrm{O}$

$$
\mathrm{CH}_{3} \mathrm{C}(\mathrm{O}) \mathrm{CH}_{2} \mathrm{O}_{2}+\mathrm{NO} \rightarrow \mathrm{CH}_{3} \mathrm{C}(\mathrm{O})+\mathrm{CH}_{2} \mathrm{O}+\mathrm{NO}_{2}
$$

$\mathrm{CH}_{3} \mathrm{C}(\mathrm{O})+\mathrm{O}_{2}+\mathrm{M} \rightarrow \mathrm{CH}_{3} \mathrm{C}(\mathrm{O}) \mathrm{O}_{2}+\mathrm{M}$

Although the production of peracetic acid, $\mathrm{CH}_{3} \mathrm{C}(\mathrm{O}) \mathrm{OOH}$, in reaction (1) has clearly been shown in the laboratory $[4,5,7]$, no measurements of its atmospheric abundance have yet been made. On the other hand, acetic acid has been detected in the gas phase and has also been shown to be a ubiquitous component of rainwater (e.g. [10-17]). Atmospheric loss processes for these species (particularly peracetic acid) have yet to be firmly established. Heterogeneous processes (i.e. wet and dry deposition) will likely play a role, as will reaction with $\mathrm{OH}$ [18]. While acetic acid possesses no measurable absorption in the actinic region of the spectrum $(\lambda>290 \mathrm{~nm})[19]$ and thus will not be subject to photolytic destruction in the troposphere, no gas phase UV absorption spectra for peracetic acid have been reported to date. 
In this work, the first gas phase spectrum of peracetic acid is reported over the range $200-350 \mathrm{~nm}$. Since acetic acid is found as an impurity in the peracetic acid samples used, its spectrum was also studied in the same wavelength region. Measurements were made over a range of pressures, allowing for the deconvolution of the acetic acid monomer and dimer spectra. Comparisons are made with previously reported acetic acid spectra. The impact of photolysis on the atmospheric destruction of peracetic acid is also discussed.

\section{Experimental}

Spectral measurements in the near UV were made using a conventional spectrometer system, which has been described previously $[20,21]$. Briefly, measurements were made in a $90 \mathrm{~cm}$ long, temperature-regulated cylindrical pyrex absorption cell, equipped with Suprasil quartz windows. Measurements were made over a range of temperatures (acetic acid at $270,298,325$, and $345 \mathrm{~K}$; peracetic acid at 248 and $298 \mathrm{~K}$ ). The beam from a deuterium lamp is collimated, passed through the absorption cell, and is then focussed onto the entrance slit of a $0.3 \mathrm{~m}$ Czerny-Turner spectrograph equipped with a 300 groove $\mathrm{mm}^{-1}$ grating, which disperses the light onto a 1024-pixel diode array detector (EG\&G Model 1420). Under this configuration, the spectral resolution of the spectrometer system is $0.6 \mathrm{~nm}$ with each pixel separated in wavelength by about $0.25 \mathrm{~nm}$. Wavelength calibrations were done via interpolation between the positions of the emission lines of a low pressure mercury lamp. Spectra were typically obtained via the summation of 100 exposures of the diode array, each of $0.2 \mathrm{~s}$ duration. Raw spectral data at each pixel, $I(\lambda)$, were converted to absorbance units (base e) via comparison with a reference spectrum, $I_{0}(\lambda)$, recorded with the absorption cell evacuated:

$A(\lambda)=\ln \left\{\frac{I_{\mathrm{o}}(\lambda)}{I(\lambda)}\right\}$

Absorption spectra were then smoothed and the smoothed data interpolated to obtain absorbance values at $0.5 \mathrm{~nm}$ intervals.

For measurements of gas phase acetic acid (monomer and dimer) spectra, vapors above a sample of glacial acetic acid (99.8\%, Aldrich) were added to the absorption cell using a standard vacuum system. The glacial acetic acid sample was first degassed via repetitive freeze-pump-thaw cycles. Spectra were obtained at pressures ranging from 0.12 to 3.6 Torr. Determination of the monomer and dimer absorption cross sections from the measured spectra required a complex deconvolution procedure. This procedure, and the uncertainties in the resulting data, are described in the results section.

Peracetic acid was purchased from Aldrich (32 wt.\% in dilute aqueous acetic acid solution). Before use, the sample was pumped on for a few hours to approximately $20 \%$ of its initial volume to remove the majority of the water. Contents of the vapors above the remaining sample were analyzed by
FTIR spectroscopy [9] to determine the level of water and acetic acid impurity; typically, these vapors were found to contain about $60-70 \%$ peracetic acid, with the remainder being acetic acid and water (each $\approx 15 \%$ ). The same sample was then used to make a series of UV measurements, with total sample pressure varied over the range 0.08 to 1.0 Torr. IR absorption measurements conducted before and after the UV measurements showed no measurable change in the sample purity. $\mathrm{H}_{2} \mathrm{O}_{2}$, a potential impurity in the peracetic acid samples, is known to be rapidly converted to $\mathrm{H}_{2} \mathrm{O}$ in both our IR and UV absorption cells, and thus is unlikely to make any contribution to the spectral measurements.

UV absorption cross sections were obtained in conventional fashion using Beer's law:

$A(\lambda)=\sigma(\lambda) l c$

Cross sections were obtained from the slope of plots of $A / l$ versus concentration at each wavelength (where $l$ is the absorption pathlength, $c$ is the peracetic acid concentration, and $\sigma$ is the absorption cross section). Concentrations used in the analysis were corrected for the presence of $\mathrm{H}_{2} \mathrm{O}$ and acetic acid impurity (as determined from the infrared spectra), and measured absorbances were corrected for a minor $(<5 \%)$ spectral contribution from acetic acid monomer and dimer.

\section{Results and discussion}

\subsection{Acetic acid}

The dimerization of acetic acid is a well characterized process, with the recommended value for the dimerization equilibrium constant given as follows [4,22]: $K_{\mathrm{eq}}=P_{\mathrm{D}} / P_{\mathrm{M}}^{2}=$ $7.1 \times 10^{-9} \exp (7705 / T)$, for dimer $\left(P_{\mathrm{D}}\right)$ and monomer $\left(P_{\mathrm{M}}\right)$ partial pressures given in units of atm. Thus, under the conditions of our experiments, measured absorbance spectra will contain contributions from both the monomer and the dimer:

$\frac{A(\lambda)}{l}=\sigma_{\mathrm{M}}(\lambda)[\mathrm{M}]+\sigma_{\mathrm{D}}(\lambda)[\mathrm{D}]$

where $A(\lambda)$ is the measured absorbance at wavelength $\lambda, l$ is the absorption pathlength, $\sigma_{\mathrm{M}}(\lambda)$ and $\sigma_{\mathrm{D}}(\lambda)$ are the absorption cross sections for the monomer and dimer at wavelength $\lambda$, and $[\mathrm{M}]$ and $[\mathrm{D}]$ are the concentrations of the monomer and dimer in units of molecule $\mathrm{cm}^{-3}$, respectively.

Absorption cross sections for the acetic acid monomer and dimer were obtained as follows. First, composite spectra were obtained at a number of different total pressures (ranging from 0.12 to 3.6 Torr at $298 \mathrm{~K}$ and above, and from 0.15 to 1.5 Torr at $270 \mathrm{~K}$ ). Concentrations for the monomer and dimer were then calculated for each pressure using $K_{\text {eq }}$ given above, and a series of equations of the form (C) was thus created for each wavelength interval (i.e. each $0.5 \mathrm{~nm}$ ) in which the only unknowns are the monomer and dimer cross sections, $\sigma_{M}(\lambda)$ and $\sigma_{D}(\lambda)$. Cross sections for both the 


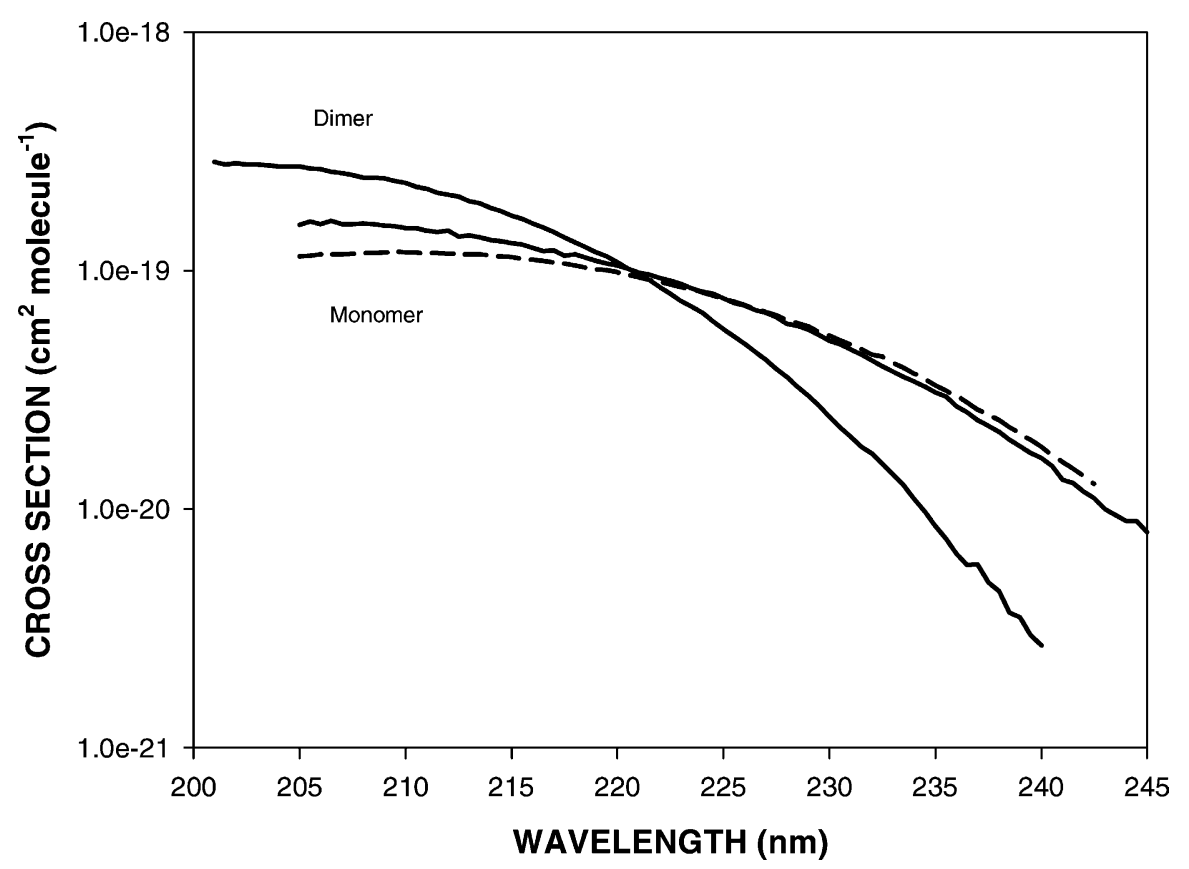

Fig. 1. Gas phase acetic acid (monomer and dimer) spectra obtained in this work. Solid lines, $298 \mathrm{~K}$ spectra; dashed line, acetic acid spectrum at $345 \mathrm{~K}$.

monomer and dimer were then obtained at each wavelength from a least-squares fitting procedure, in which $\sigma_{M}(\lambda)$ and $\sigma_{\mathrm{D}}(\lambda)$ were varied to achieve best agreement between measured and calculated (Eq. (C)) values of $A(\lambda)$.

Uncertainties in the acetic acid cross section data arise from errors in absorbance, pathlength, and pressure, and also from uncertainty in the dimerization equilibrium constant, in the measurement of temperature (which impacts the equilibrium), and in the fitting procedure. Estimated uncertainties for the monomer cross sections are $\pm 15 \%$ below $220 \mathrm{~nm}$, and $\pm 35 \%$ near $240 \mathrm{~nm}$. Uncertainties in the dimer cross sections are probably slightly higher, $\pm 25 \%$ below $220 \mathrm{~nm}$ and $\pm 50 \%$ near $235 \mathrm{~nm}$.

Room temperature spectra for the monomer and dimer obtained via this fitting procedure are shown as the solid lines in Fig. 1. The cross section data are also given at $2 \mathrm{~nm}$ intervals in Table 1 . The analysis clearly shows that the two spectra differ from each other in both shape and intensity. The monomer spectrum displays a broad maximum near $207 \mathrm{~nm}$, with $\sigma_{\mathrm{M}}(207 \mathrm{~nm})=(1.5 \pm 0.2) \times 10^{-19} \mathrm{~cm}^{2}$ per molecule, and monotonically decreases in intensity with increasing wavelength. The absorption maximum for the dimer, on the other hand, appears at shorter wavelength $\left(\lambda_{\max }<205 \mathrm{~nm}\right)$, and is about twice as intense as the monomer, $\sigma_{\mathrm{D}}(205 \mathrm{~nm})$ $=(2.5 \pm 0.5) \times 10^{-19} \mathrm{~cm}^{2}$ per molecule. The decrease in cross section with increasing wavelength is more rapid for the dimer than for the monomer, resulting in higher values of $\sigma_{\mathrm{M}}(\lambda)$ than $\sigma_{\mathrm{D}}(\lambda)$ at $\lambda>225 \mathrm{~nm}$.

Analogous sets of measurements were taken at 270, 325, and $345 \mathrm{~K}$. Measurements at lower temperatures were not possible, due to the low vapor pressure of the acetic acid samples. As an example, the spectrum of the monomer obtained at $345 \mathrm{~K}$ is shown as the dashed line in Fig. 1 . The monomer spectrum appears to be slightly broader at higher temperature (lower cross section near the peak, higher at longer wavelengths compared to the $298 \mathrm{~K}$ spectrum), though the observed changes over the full range of temperatures examined are probably comparable in magnitude to the uncertainty in the measurements. The retrieved dimer spectra at different temperatures showed no discernible trend with temperature; cross sections obtained near the peak of the spectrum varied by about $\pm 10 \%$ from temperature to

Table 1

Gas phase UV absorption cross sections for acetic acid monomer and dimer at $298 \mathrm{~K}$, at $2 \mathrm{~nm}$ intervals

\begin{tabular}{lll}
\hline $\begin{array}{l}\text { Wavelength } \\
(\mathrm{nm})\end{array}$ & $\begin{array}{l}\text { Monomer cross section } \\
\left(10^{-21} \mathrm{~cm}^{2} \text { per molecule }\right)\end{array}$ & $\begin{array}{l}\text { Dimer cross section } \\
\left(10^{-21} \mathrm{~cm}^{2} \text { per molecule }\right)\end{array}$ \\
\hline 210 & 151 & 234 \\
212 & 147 & 209 \\
214 & 135 & 184 \\
216 & 125 & 158 \\
218 & 117 & 132 \\
220 & 105 & 109 \\
222 & 93.3 & 85.4 \\
224 & 81.9 & 66.8 \\
226 & 71.7 & 49.5 \\
228 & 60.0 & 36.0 \\
230 & 50.9 & 24.5 \\
232 & 42.0 & 17.1 \\
234 & 34.4 & 11.1 \\
236 & 27.1 & 6.5 \\
238 & 21.1 & 4.5 \\
240 & 16.4 & 2.7 \\
242 & 11.9 & \\
244 & 8.9 & \\
\hline
\end{tabular}


temperature, while the scatter was of order $\pm 40 \%$ at $240 \mathrm{~nm}$. As discussed above, this scatter is likely due to uncertainties inherent to the measurement of temperature and in the analysis procedure.

Comparisons of our data with previous work [19,23-25] are difficult to do in most cases, as quantitative accounting for the presence of both the monomer and dimer were seldom carried out and insufficient details are given to assess the relative dimer and monomer contributions to the measured spectra. In fact, other than a single wavelength determination by Singleton et al. [25], absorption cross sections for the dimer have not been previously reported. Singleton et al. [25] used a procedure similar to ours to obtain monomer and dimer absorption cross sections at $222 \mathrm{~nm}$; their data are in reasonable agreement with ours (their monomer value is about 25\% lower and their dimer value about $15 \%$ higher than our values). Spectra reported by both Calvert and Pitts [19] and by Suto et al. [24] possess shapes similar to that of the dimer, but with cross sections similar in magnitude to the monomer at short wavelength (see Fig. 1). Both of these studies indicate the likelihood of contribution to the spectrum from the dimer, but insufficient details are given to make any quantitative assessment. The liquid phase acetic acid spectrum of Giguère and Olmos [26], reported over the range $225-245 \mathrm{~nm}$, also resembles more closely that of the dimer than that of the monomer. The spectrum reported by Barnes et al. [23], attributed to the monomer, is very similar in shape and magnitude to our monomer spectrum. As alluded to in the introduction, the lack of any significant absorption in the near UV portion of the spectrum (i.e. in the actinic region beyond $290 \mathrm{~nm}$ ) means that photolysis will not contribute to the tropospheric destruction of acetic acid.

\subsection{Peracetic acid}

The peracetic acid UV absorption spectrum $(298 \mathrm{~K}$, 205-340 nm), obtained using a conventional Beer's law analysis (see Section 2), is shown in Fig. 2. Cross sections are given at $2 \mathrm{~nm}$ intervals in Table 2. At short wavelengths, uncertainties in the peracetic acid cross section data are dominated by the uncertainty in the peracetic acid concentration determination $( \pm 10 \%)$, with minor $( \pm 1 \%)$ contributions from errors in the measurement of absorbance, pressure and pathlength. At longer wavelengths, relative uncertainties in the absorbance measurement increase as the cross sections decrease. Overall, estimated uncertainties range from $\pm 10 \%$ at $\lambda<290 \mathrm{~nm}$, to $\pm 20 \%$ at $320 \mathrm{~nm}$, and about $\pm 50 \%$ at $330 \mathrm{~nm}$.

Absorption cross sections are seen to decrease in a monotonic, pseudo-exponential fashion over the range measured, decreasing from a value near $10^{-18} \mathrm{~cm}^{2}$ per molecule at $205 \mathrm{~nm}$ to about $10^{-22} \mathrm{~cm}^{2}$ per molecule at $340 \mathrm{~nm}$. Though measurements are difficult to make at low temperature due to the reduced vapor pressure, the $248 \mathrm{~K}$ spectrum shows an apparently faster fall-off with wavelength than was the case at $298 \mathrm{~K}$.

To the best of our knowledge, the gas phase peracetic acid absorption spectrum has not been previously measured. However, Giguère and Olmos [26] have reported peracetic acid spectra in both aqueous and isooctane solution, which

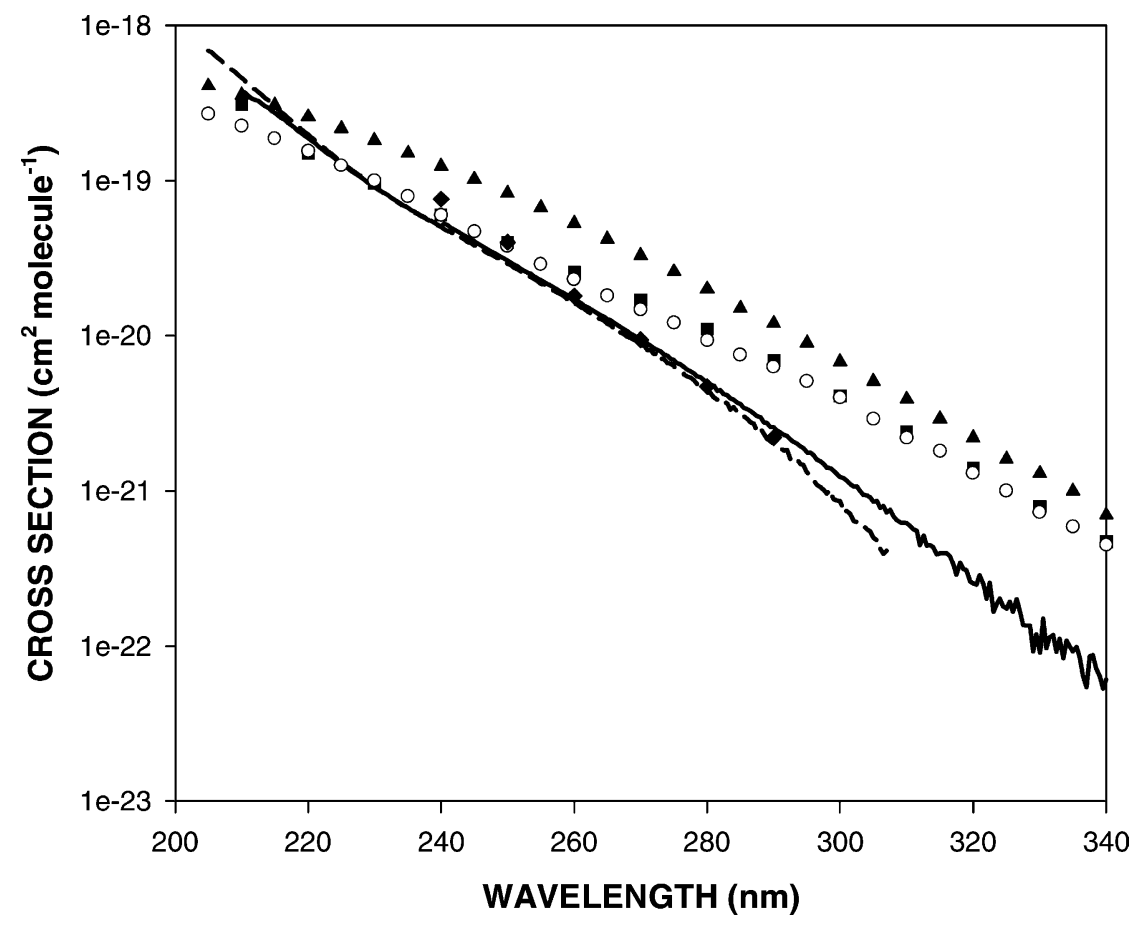

Fig. 2. Gas phase peracetic acid spectra at $298 \mathrm{~K}$ (solid line, this work) and $248 \mathrm{~K}$ (dashed line, this work). Other data shown are for peracetic acid in isooctane solution (diamonds [26]), gas phase $\mathrm{H}_{2} \mathrm{O}_{2}$ (triangles [18]), $\mathrm{CH}_{3} \mathrm{OOH}$ (squares [18]), and $\mathrm{HOCH}_{2} \mathrm{OOH}$ (open circles [27]). 
Table 2

UV absorption cross sections for peracetic acid in the gas phase, at $2 \mathrm{~nm}$ intervals

\begin{tabular}{|c|c|}
\hline Wavelength (nm) & $\begin{array}{l}\text { Cross section } \\
\left(10^{-21} \mathrm{~cm}^{2} \text { per molecule }\right)\end{array}$ \\
\hline 210 & 381 \\
\hline 212 & 331 \\
\hline 214 & 295 \\
\hline 216 & 254 \\
\hline 218 & 217 \\
\hline 220 & 189 \\
\hline 222 & 160 \\
\hline 224 & 139 \\
\hline 226 & 120 \\
\hline 228 & 105 \\
\hline 230 & 91.0 \\
\hline 232 & 80.1 \\
\hline 234 & 70.3 \\
\hline 236 & 63.1 \\
\hline 238 & 56.1 \\
\hline 240 & 50.3 \\
\hline 242 & 48.3 \\
\hline 244 & 43.1 \\
\hline 246 & 38.2 \\
\hline 248 & 34.1 \\
\hline 250 & 30.5 \\
\hline 252 & 27.1 \\
\hline 254 & 24.2 \\
\hline 256 & 21.6 \\
\hline 258 & 19.3 \\
\hline 260 & 17.1 \\
\hline 262 & 15.3 \\
\hline 264 & 13.5 \\
\hline 266 & 12.1 \\
\hline 268 & 10.6 \\
\hline 270 & 9.45 \\
\hline 272 & 8.35 \\
\hline 274 & 7.42 \\
\hline 276 & 6.51 \\
\hline 278 & 5.74 \\
\hline 280 & 5.06 \\
\hline 282 & 4.44 \\
\hline 284 & 3.86 \\
\hline 286 & 3.34 \\
\hline 288 & 2.97 \\
\hline 290 & 2.56 \\
\hline 292 & 2.26 \\
\hline 294 & 1.93 \\
\hline 296 & 1.70 \\
\hline 298 & 1.41 \\
\hline 300 & 1.23 \\
\hline 302 & 1.07 \\
\hline 304 & 0.94 \\
\hline 306 & 0.78 \\
\hline 308 & 0.69 \\
\hline 310 & 0.62 \\
\hline 312 & 0.45 \\
\hline 314 & 0.44 \\
\hline 316 & 0.40 \\
\hline 318 & 0.35 \\
\hline 320 & 0.25 \\
\hline 322 & 0.20 \\
\hline 324 & 0.20 \\
\hline 326 & 0.17 \\
\hline 328 & 0.14 \\
\hline 330 & 0.09 \\
\hline 332 & 0.11 \\
\hline 334 & 0.11 \\
\hline 336 & 0.09 \\
\hline 338 & 0.09 \\
\hline 340 & 0.06 \\
\hline
\end{tabular}

appear very similar to each other and to our data (see Fig. 2). The peracetic acid spectrum also bears a resemblance to those of other peroxides $\left(\mathrm{H}_{2} \mathrm{O}_{2}, \mathrm{CH}_{3} \mathrm{OOH}\right.$, and $\left.\mathrm{HOCH}_{2} \mathrm{OOH}\right)$ for which data are available [18,27], though the peracetic acid spectrum is weaker and falls off more steeply with wavelength than do the spectra of these other species.

Possible tropospheric removal processes for gas phase peracetic acid include photolysis, reaction with $\mathrm{OH}$, and removal by heterogeneous processes (wet and dry deposition). Using the absorption cross sections obtained herein, tabulated solar flux data [28], and assuming a photodissociation quantum yield of unity, the peracetic acid photolysis lifetime is estimated to be about 3-4 weeks, for typical mid-latitude summer conditions, roughly independent of altitude. The rate coefficient for reaction of $\mathrm{OH}$ with peracetic acid has not been measured but, by analogy to the reactivity of $\mathrm{OH}$ with $\mathrm{H}_{2} \mathrm{O}_{2}$ and $\mathrm{CH}_{3} \mathrm{OOH}$ [18], a value on the order of (1-5) $\times 10^{-12} \mathrm{~cm}^{3}$ per molecule $\mathrm{s}^{-1}$ seems plausible, which would imply a peracetic acid lifetime against $\mathrm{OH}$ reaction of about 2-12 days. Peracetic acid is only moderately soluble in aqueous solution, $H=670 \mathrm{M} \mathrm{atm}^{-1}[29,30]$ at $298 \mathrm{~K}$, and hence wet and dry deposition processes [31,32] are not likely to be rapid (lifetimes of weeks or more). Thus, photolysis of peracetic acid will occur on a timescale that is comparable to other loss processes, and will play at least a minor role in its tropospheric removal. Studies of its rate coefficient with $\mathrm{OH}$ would clearly be useful in establishing more firmly the tropospheric lifetime of this species.

\section{Acknowledgements}

The National Center for Atmospheric Research is operated by the University Corporation for Atmospheric Research, under the sponsorship of the National Science Foundation. This work was funded in part by the NASA Upper Atmosphere Research Program. Thanks are due to Alan Fried and Mary Barth (both of NCAR) for their careful reading of the manuscript.

\section{References}

[1] G.P. Brasseur, J.J. Orlando, G.S. Tyndall (Eds.), Atmospheric Chemistry and Global Change, Oxford University Press, New York, 1999.

[2] R. Atkinson, J. Phys. Chem. Ref. Data Monogr. 2 (1997) 1.

[3] R. Atkinson, J. Phys. Chem. Ref. Data 26 (1997) 215.

[4] M.A. Crawford, T.J. Wallington, J.J. Szente, M.M. Maricq, J.S. Francisco, J. Phys. Chem. A 103 (1999) 365.

[5] H. Niki, P.D. Maker, C.M. Savage, L.P. Breitenbach, J. Phys. Chem. 89 (1985) 588.

[6] G.K. Moortgat, B. Veyret, R. Lesclaux, Chem. Phys. Lett. 160 (1989) 443.

[7] O. Horie, G.K. Moortgat, J. Chem. Soc., Faraday Trans. 88 (1992) 3305.

[8] M.E. Jenkin, R.A. Cox, M. Emrich, G.K. Moortgat, J. Chem. Soc., Faraday Trans. 89 (1993) 2983. 
[9] J.J. Orlando, G.S. Tyndall, L. Vereecken, J. Peeters, J. Phys. Chem. A 104 (2000) 11578

[10] M. Andreae, R.W. Talbot, T.W. Andreae, R.C. Harriss, J. Geophys. Res. 93 (1988) 1616.

[11] D.J. Jacob, S.C. Wofsy, J. Geophys. Res. 93 (1988) 1477.

[12] T. Reiner, O. Mohler, F. Arnold, J. Geophys. Res. 104 (1999) 13943.

[13] R.W. Talbot, M.O. Andreae, H. Berresheim, D.J. Jacob, K.M. Beecher, J. Geophys. Res. 95 (1990) 16799.

[14] G.A. Dawson, J.C. Farmer, J.L. Moyers, Geophys. Res. Lett. 7 (1980) 725.

[15] D. Grosjean, Env. Sci. Technol. 23 (1989) 1506.

[16] J.E. Lawrence, P. Koutrakis, Env. Sci. Technol. 28 (1994) 957.

[17] R.W. Talbot, et al., J. Geophys. Res. 100 (1995) 9335.

[18] W.B. DeMore, S.P. Sander, D.M. Golden, R.F. Hampson, M.J. Kurylo, C.J. Howard, A.R. Ravishankara, C.E. Kolb, M.J. Molina, Chemical kinetics and photochemical data for use in stratospheric modeling, Evaluation no. 12, NASA JPL Publication 97-4, 1997.
[19] J.G. Calvert, J.N. Pitts Jr., Photochemistry, Wiley, New York, 1966. [20] T.A. Staffelbach, J.J. Orlando, G.S. Tyndall, J.G. Calvert, J. Geophys. Res. 100 (1995) 14189.

[21] J.J. Orlando, G.S. Tyndall, J.-M. Fracheboud, E. Estupinan, S. Haberkorn, A. Zimmer, Atmos. Environ. 33 (1999) 1621.

[22] J. Chao, B.J. Zwolinski, J. Phys. Chem. Ref. Data 7 (1978) 363.

[23] E.E. Barnes, W.T. Simpson, J. Chem. Phys. 39 (1963) 670.

[24] M. Suto, X. Wang, L.C. Lee, J. Phys. Chem. 92 (1988) 3764.

[25] D.L. Singleton, G. Paraskevopoulos, R.S. Irwin, J. Phys. Chem. 94 (1990) 695

[26] P.A. Giguère, A.W. Olmos, Can. J. Chem. 34 (1956) 689.

[27] S. Bauerle, G.K. Moortgat, Chem. Phys. Lett. 309 (1999) 43.

[28] S. McKeen, NOAA Aeronomy Lab, personal communication (1991).

[29] J. Lind, G. Kok, J. Geophys. Res. 91 (1986) 7889.

[30] J. Lind, G. Kok, J. Geophys. Res. 99 (1994) 21119.

[31] F. Giorgi, W.L. Chameides, J. Geophys. Res. 90 (1985) 7872.

[32] M.L. Wesely, Atmos. Environ. 23 (1989) 1293. 